\title{
The effect of regular aerobic exercise on sleep quality and fatigue among female student dormitory residents
}

\author{
Maryam Ezati ${ }^{1}$, Maryam Keshavarz ${ }^{1 *}$, Zahra Amirkhanzadeh Barandouzi ${ }^{2}$ and Ali Montazeri ${ }^{3}$
}

\begin{abstract}
Background: Emerging research shows a high prevalence of fatigue and sleep problems among university students. The present study evaluates the effects of regular aerobic exercise on sleep quality and fatigue level among female students (ages 18-26) who reside in dormitories.

Methods: This quasi-experimental study involving 67 participants consisted of one experimental group (i.e., assigned aerobic exercise) and one control group (i.e., not assigned aerobic exercise). Participants in the experimental group received three one-hour sessions aerobic exercise weekly ranging from mild to moderate intensity for eight-week. Sleep quality and fatigue level were evaluated using the Pittsburgh Sleep Quality Index (PSQI) and standard Multidimensional Fatigue Inventory (MFI-20), respectively. These variables were assessed at baseline, week four, and week eight of the study.
\end{abstract}

Results: After four and 8 weeks of the intervention, participants in the aerobic group showed improvement in the score of sleep quality ( $p<0.001$ and $p<0.0001$, respectively) and its components (except for sleep duration after 4 weeks intervention). Also, aerobic exercise resulted in a significant reduction of the total score of fatigue and its dimensions in weeks four and eight, compared to the control group $(p<0.001)$.

Conclusions: Four-week aerobic exercise with mild intensity had no significant effect on sleep duration. Conversely, intensified aerobic exercise for 8 weeks influenced all components of sleep quality.

Trial registration: The study was registered on 6/2/2015 in the Iranian Registry of Clinical Trials (IRCT) with number IRCT201412282324N15.

Keywords: Aerobic exercise, Sleep quality, Fatigue, Dormitory students

\section{Background}

Sleep is a biological process that is necessary for optimal neurologic function, as well as systematic biology, including metabolism, appetite regulation, immunity, hormonal balance, and cardiovascular system [1,2]. Sleep disorders affect a considerable number of people globally and may be increasing in prevalence [3]. University students with

\footnotetext{
* Correspondence: keshavarz.m@iums.ac.ir

'Department of Midwifery and Reproductive Health, Faculty of Nursing and Midwifery, Iran University of Medical Sciences, Tehran, Iran

Full list of author information is available at the end of the article
}

sleep problems may also experience a decline in health and academic performance [4]. In different surveys in the United States, the prevalence of poor sleep quality has reportedly been between 27 and $60 \%$ of university students $[4,5]$. In one study, the prevalence of sleep disorders in Iranian University students was reported by $40.6 \%$ [6]. It appears that residency in dormitories has been cited as an influential factor that affects sleep quality in students [7]. Results of a survey from 23 countries revealed that physical activity was below the recommended levels for the majority of university students. More than $50 \%$ of 
American university students are not sufficiently active [8]. Also, there is a growing concern for the physical inactivity of Iranian university students [9].

The American Academy of Sleep Medicine (AASM) recommends regular physical activity for proper sleep hygiene. AASM suggests exercise can be a non-pharmacological intervention for sleep quality improvement [10]. In a systematic review of 34 studies, 29 studies reported a positive effect of physical activity on sleep quality and its duration among all age groups [11]. Although numerous studies reported the effectiveness of exercise on sleep quality of people in different age ranges across various chronic conditions [12-19], there are contradictory results regarding the impact of exercise on the sleep quality of university students, especially those that reside in dormitories [20-24]. In a quasi-experimental study conducted in Iran, exercise did not have a significant effect on the sleep quality of students [20]. Some studies have shown that gender is an indicator of sleep quality [25], with women reportedly suffering from sleep dysfunction more than men [21, 25]. The intensity of exercise is another factor that was evaluated in limited studies $[18,23]$.

Daily fatigue is one of the consequences people with sleep dysfunction deal with [26]. While the effect of exercise on fatigue has been evaluated in chronic diseases [27, 28], there are few studies on young adults, as well as in dormitory students. The present study was designed to investigate the effects of an eight-week aerobic exercise intervention on sleep quality and daily fatigue. It was hypothesized that regular aerobic exercise with increasing intensity would improve sleep quality and decrease fatigue level among female students living in dormitories.

\section{Methods}

\section{Study design and sampling}

This study was conducted from October to December 2015. Two out of eight dormitories at the Iran University of Medical Sciences (IUMS) were randomly selected. One of the randomly selected dormitories was the experimental group, whereas the second served as the control group. A non-probability sampling method was used to enroll participants in each of the two selected dormitories. The use of quasi-experimental design minimized the influence of confounding covariates such as students' interactions regarding the intervention and the process of the study.

\section{Participants}

Forty eligible volunteers were enrolled from each of the two dormitories. Participants were Iranian females between 18 and 26 years of age who met the following criteria: $\mathrm{BMI}<29 \quad(\mathrm{~kg} / \mathrm{m} 2)$, non-smoking, no use of acupuncture or other complementary medicines over the last 6 months, and no exposure to stressful events over the past 3 months. They were not enrolled or later dropped out based on the following criteria: a presence of physical or mental illness or surgical history, unwillingness to continue the study, absent for three consecutive or five non-consecutive exercise sessions, involvement in daily physical activity beyond the study protocol, the use of complementary medicines or herbal therapy that influences sleep or fatigue level (i.e., energy-enhancing drugs and/or sleeping medications).

\section{Tools}

The Pittsburgh Sleep Quality Index (PSQI) was used to measure sleep quality [29]. This tool consists of seven areas including: subjective sleep quality, sleep latency, sleep duration, sleep efficiency (the percentage of sleeping time during the time in bed), sleep disturbances (night time waking), use of sleeping medications, and daytime dysfunction (distress and impaired daytime functioning). Scoring of answers was based on a scale of 0 to 3 (total score of 21). Higher scores indicate poorer sleep quality [29]. In the present study, all participants received a score of zero for area six (the use of sleeping medications) since we did not allow students who took sleeping medication to participate. Several studies have evaluated the validity and reliability of the PSQI as a measurement for sleep quality [30-32]. In one Iranian study, the reliability of the Persian version of the PSQI had a Cronbach's alpha coefficient of 0.77 [33]. In our sample, the PSQI Cronbach's alpha coefficient was 0.80 .

The Multidimensional Fatigue Inventory (MFI-20) was used to assess the fatigue level. This instrument consists of a 20-item survey that covers the following five dimensions: general fatigue (impairment of overall daytime functioning), physical fatigue (body tiredness), mental fatigue (fatigue related to cognition), reduced activity, and reduced motivation. The score of each dimension ranges from 4 to 20 . The composite score of fatigue level is the sum of the five dimensions' scores (i.e., composite score ranges from 20 to 100). Higher scores indicate greater fatigue. The validity and reliability of MFI-20 have been tested previously [34]. The reliability of the Persian version of MFI-20 was evaluated in Multiple Sclerosis [35]. The reliability of the MFI-20 in the present sample resulted in a Cronbach's alpha coefficient of 0.85 .

\section{Study procedure}

Following a discussion of the research objectives and informed consent, the participants in both experimental and control groups individually filled out a demographic questionnaire, the PSQI, and the MFI- 20.

At the beginning of each session, a German Buere digital heart rate display was worn around the wrist of the participants. The participants in the experimental group collectively received aerobic exercise plan from an exercise specialist in the dormitories' gym. The participants exercised with the 
trainer during three one-hour sessions weekly for eight consecutive weeks. Each session included a $10 \mathrm{~min}$ warm-up (marching, top-to-bottom movements), $35 \mathrm{~min}$ of basic aerobic exercises (10 min combined exercises, $20 \mathrm{~min}$ of mental activity, $5 \mathrm{~min}$ mat exercise), and a $15 \mathrm{~min}$ cool-down. The schedule was from 17:00 to $18: 00 \mathrm{pm}$. The subjects performed the exercises at $45-50 \%$ of maximum heart rate (mild intensity) during the first 4 weeks of intervention and at $65-70 \%$ of maximum heart rate (moderate intensity) during the second 4 weeks of the intervention [16]. Intensities were estimated using Karvonen's formula (i.e., maximum heart rate minus the subject's mean age [31]. At the end of the fourth and eighth weeks of the intervention, all participants in the study filled out the PSQI and MFI-20 questionnaires. Students in the control group did not receive any intervention and performed their daily routines (Fig. 1).

\section{Sample size}

The sample size was estimated based on the expected difference in study outcomes between the experimental and control groups. To be able to detect a $25 \%$ difference in sleep quality between two groups, a study with a sample size of 72 would be required (36 per each group). As such, the study would have a power of $80 \%$ at a $5 \%$ significance level. The effect size was assumed to be 1 . However, this study recruited 40 students for each group to avoid follow-up losses.

\section{Statistical tests}

Results were analyzed using SPSS version 25. KolmogorovSmirnow was used to test the normality of the variables. All variables were identified as non-normal (except BMI). The
Mann-Whitney test was utilized for variables with nonnormal distribution. An independent sample T-test was utilized for BMI. To compare the qualitative data, Chi-square and the exact Fisher test were used. Friedman's test was utilized to compare each component of sleep quality at different time periods in each group.

\section{Results}

A total of 67 participants, 32 participants in the experimental group and 35 participants in the control group, completed this eight-week study (Fig. 2). There were no significant differences in the demographic characteristics (Table 1), sleep quality (Table 2), and fatigue level (Table 3) between the two groups at baseline. After four and 8 weeks of aerobic exercise, the total scores for sleep quality and its components (except for sleep duration after 4 weeks intervention) were significantly lower than the control group (Table 2). Aerobic exercise resulted in a significant reduction of the total score of fatigue level and its dimensions in weeks four and eight compared to the control group (Table 3). The results of the Friedman test indicated significant improvement in all components of sleep quality and fatigue level in the treatment group after completion of the intervention (Tables 2 and 3). Moreover, we observed a significant increase in subjective sleep quality, daytime dysfunction, and the global PSQI scores in the control group over time (Table 2).

\section{Discussion}

Our results demonstrated that 8 weeks of aerobic exercise was able to improve all sleep components, although

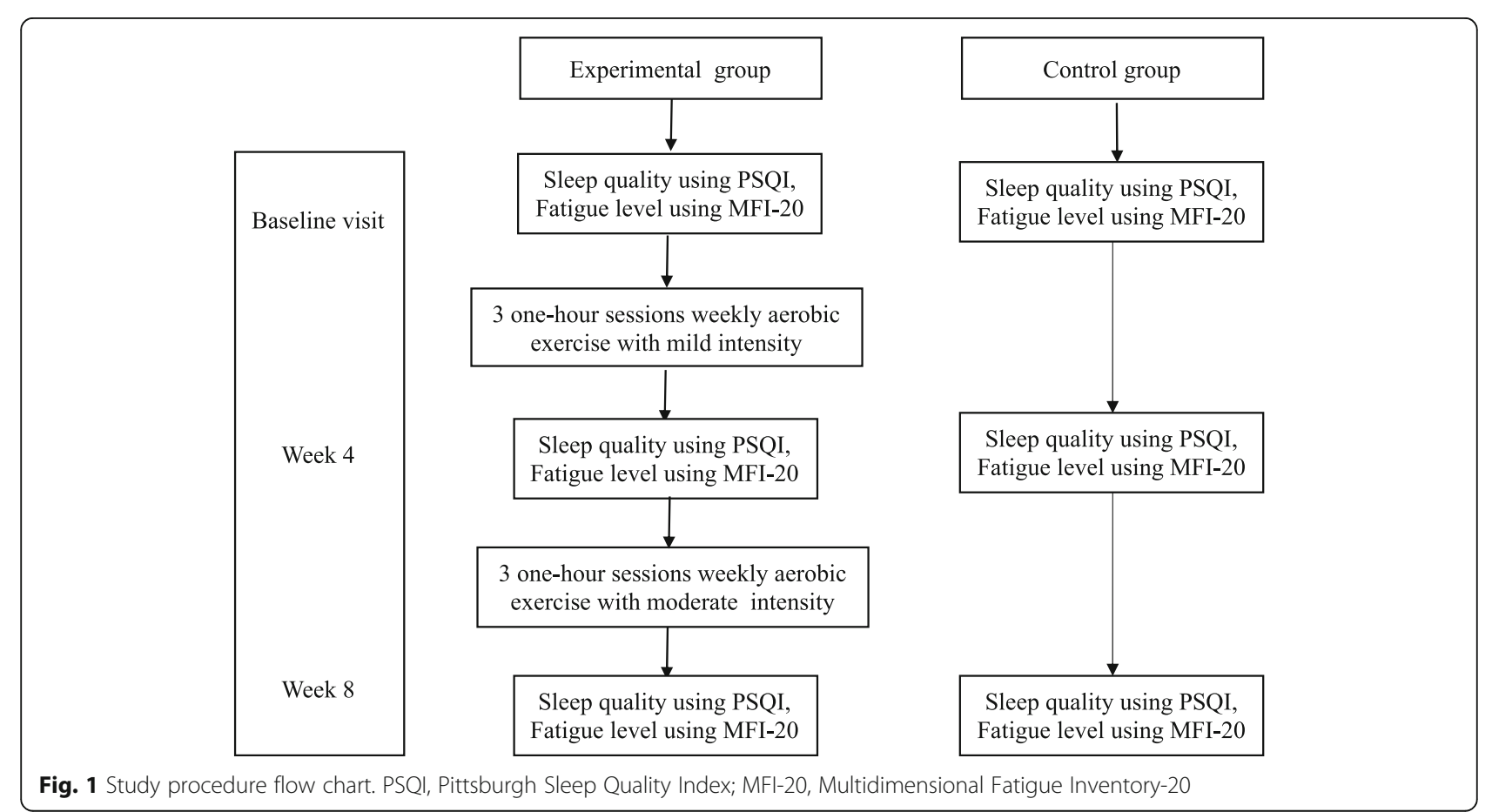




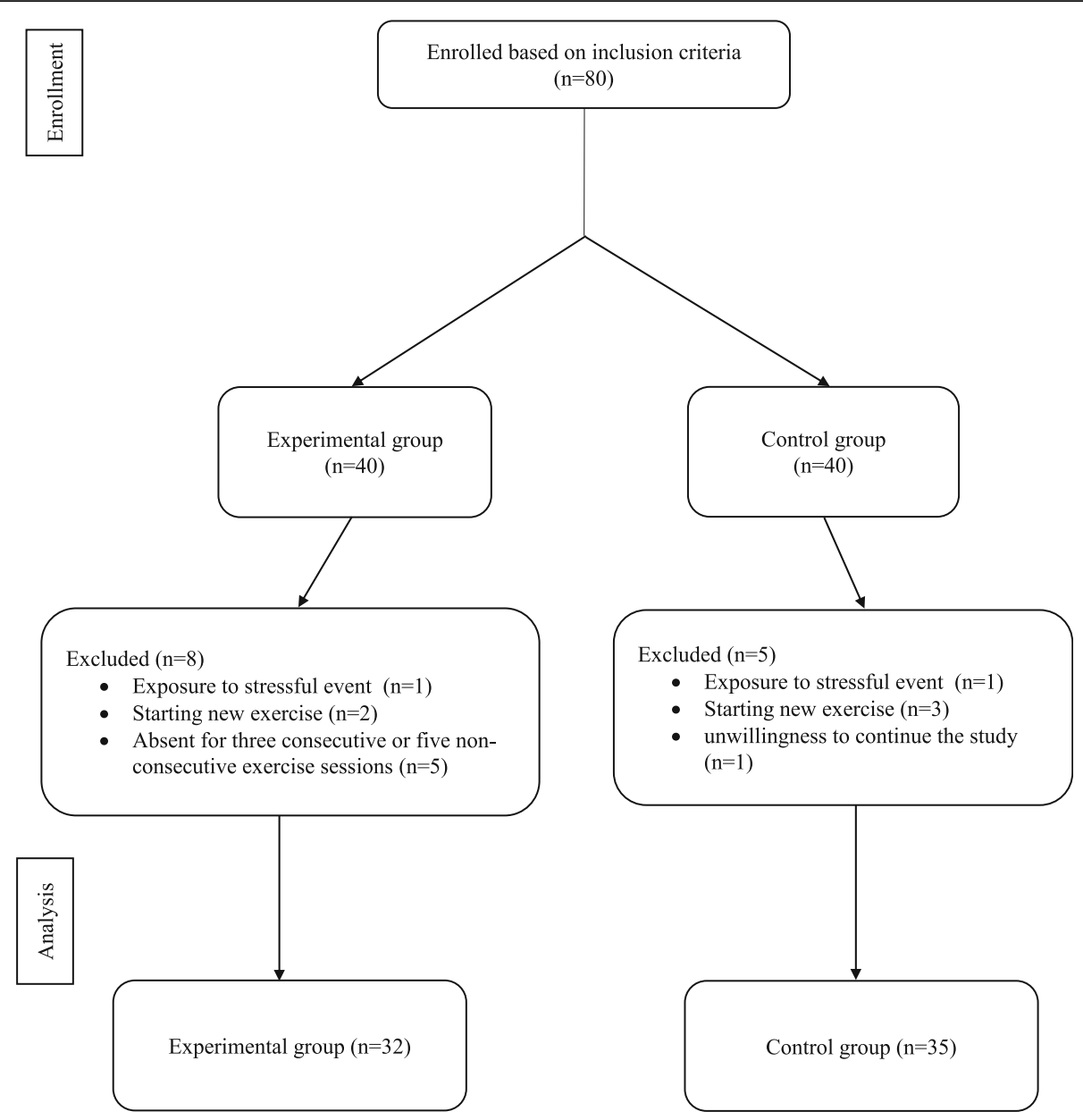

Fig. 2 Consort flow diagram

Table 1 Characteristics of the subject's demographics in the two groups

\begin{tabular}{|c|c|c|c|}
\hline & $\begin{array}{l}\text { Experimental group } \\
(n=32)\end{array}$ & $\begin{array}{l}\text { Control group } \\
(n=35)\end{array}$ & $p$-value \\
\hline Age (year) & $20.53 \pm 1.60$ & $20.08 \pm 1.31$ & $*^{*} 0.25$ \\
\hline BMI $(\mathrm{Kg} / \mathrm{m} 2)$ & $21.82 \pm 2.11$ & $22.78 \pm 2.34$ & ${ }^{* *} 0.17$ \\
\hline $\begin{array}{l}\text { Occupational status (n) }{ }^{\mathrm{a}} \\
\text { (Employed, unemployed) }^{\text {(E) }}\end{array}$ & $(6,26)$ & $(8,27)$ & ***0.68 \\
\hline Household economic (n) status (Good, Average) & $(30,2)$ & $(32,3)$ & $* * 0.17$ \\
\hline \multicolumn{4}{|l|}{ Program of study } \\
\hline Nursing \& Midwifery & $21.88 \%$ & $34.3 \%$ & \multirow[t]{4}{*}{$* * 0.31$} \\
\hline Management \& Statistics & $43.75 \%$ & $37.14 \%$ & \\
\hline Nutrition \& Health & $25 \%$ & $17.14 \%$ & \\
\hline Others & $9.37 \%$ & $11.42 \%$ & \\
\hline
\end{tabular}

* Mann Whitney

** Independent sample T-test

*** Fisher exact test

${ }^{a}$ (n) Number 
Table 2 Effect of the aerobic exercise intervention on sleep, as measured by the Pittsburgh Sleep Quality Index

\begin{tabular}{|c|c|c|c|c|c|c|c|c|c|c|c|}
\hline \multirow[t]{2}{*}{ Variable } & \multirow[t]{2}{*}{ Groups } & \multicolumn{3}{|l|}{ Baseline } & \multicolumn{3}{|c|}{4 weeks of Intervention } & \multicolumn{3}{|c|}{8 weeks of Intervention } & \multirow{2}{*}{$\begin{array}{l}\text { Friedman } \\
p \text {-value }\end{array}$} \\
\hline & & $\begin{array}{l}\text { Mean } \pm \\
S^{a}\end{array}$ & $\begin{array}{l}\text { Median } \\
(\mathrm{Cl})^{\mathrm{b}}\end{array}$ & $\begin{array}{l}p^{-} \\
\text {value }\end{array}$ & Mean \pm SD & $\begin{array}{l}\text { Median } \\
\text { (Cl) }\end{array}$ & $\begin{array}{l}p- \\
\text { value }\end{array}$ & $\begin{array}{l}\text { Mean } \pm \\
\text { SD }\end{array}$ & $\begin{array}{l}\text { Median } \\
(\mathrm{Cl})\end{array}$ & $\begin{array}{l}p^{-} \\
\text {value }^{*}\end{array}$ & \\
\hline \multirow[t]{2}{*}{$\begin{array}{l}\text { Subjective sleep } \\
\text { quality }\end{array}$} & Experimental & $\begin{array}{l}0.93 \pm \\
0.06\end{array}$ & $0(1-1)$ & 0.27 & $0.53 \pm 0.50$ & $1(0-2)$ & $<0.001$ & $\begin{array}{l}0.25 \pm \\
0.43\end{array}$ & $0(0-0)$ & $<0.001$ & $<0.001$ \\
\hline & Control & $\begin{array}{l}0.77 \pm \\
0.64\end{array}$ & $1(0-1)$ & & $1.14 \pm 0.64$ & $1(1-1)$ & & $\begin{array}{l}1.40 \pm \\
0.65\end{array}$ & $1(1-2)$ & & $<0.001$ \\
\hline \multirow[t]{2}{*}{ Sleep duration } & Experimental & $\begin{array}{l}1.34 \pm \\
0.90\end{array}$ & $1(1-2)$ & 0.16 & $0.81 \pm 0.64$ & $1(1-1)$ & 0.09 & $\begin{array}{l}0.40 \pm \\
0.49\end{array}$ & $1(0-1)$ & $<0.001$ & $<0.001$ \\
\hline & Control & $\begin{array}{l}1.05 \pm \\
0.63\end{array}$ & $1(1-1)$ & & $1.20 \pm 0.93$ & $1(1-1)$ & & $\begin{array}{l}1.20 \pm \\
0.93\end{array}$ & $1(1-1)$ & & 0.95 \\
\hline \multirow[t]{2}{*}{ Sleep latency } & $\begin{array}{l}\text { Experimental } \\
\text { Control }\end{array}$ & $\begin{array}{l}0.81 \pm \\
0.07\end{array}$ & $1(0-1)$ & 0.16 & $0.31 \pm .0 .47$ & $1(0-0)$ & 0.03 & $\begin{array}{l}0.39 \pm \\
0.18\end{array}$ & $1(0-0)$ & 0.003 & 0.002 \\
\hline & & $\begin{array}{l}0 . .54 \pm \\
0.61\end{array}$ & $1.5(0-1)$ & & $0.71 \pm 0.78$ & $1(0-1)$ & & $\begin{array}{l}0.71 \pm \\
0.78\end{array}$ & $1(0-1)$ & & 0.11 \\
\hline \multirow[t]{2}{*}{$\begin{array}{l}\text { Habitual sleep } \\
\text { efficiency }\end{array}$} & Experimental & $\begin{array}{l}1.50 \pm \\
1.52\end{array}$ & $1(0-3)$ & 0.41 & $0.46 \pm 0.62$ & $0(0-1)$ & 0.04 & $\begin{array}{l}0.15 \pm \\
0.36\end{array}$ & $0(0-0)$ & 0.03 & $<0.001$ \\
\hline & Control & $\begin{array}{l}1.80 \pm \\
1.49\end{array}$ & $3(0-3)$ & & $1.31 \pm 1.43$ & $3(0-3)$ & & $\begin{array}{l}0.48 \pm \\
0.70\end{array}$ & $0(0-1)$ & & $<0.001$ \\
\hline \multirow[t]{2}{*}{ Sleep disturbance } & Experimental & $1 \pm 0.35$ & $1(1-1)$ & 0.57 & $0.37 \pm 0.49$ & $1(0-1)$ & $\begin{array}{l}< \\
0.0001\end{array}$ & $\begin{array}{l}0.12 \pm \\
0.33\end{array}$ & $1(0-0)$ & $\begin{array}{l}< \\
0.0001\end{array}$ & $<0.001$ \\
\hline & Control & $\begin{array}{l}1.05 \pm \\
0.48\end{array}$ & $1(1-1)$ & & $0.97 \pm 0.45$ & $1(1-1)$ & & $\begin{array}{l}0.97 \pm \\
0.48\end{array}$ & $1(1-1)$ & & 1 \\
\hline \multirow[t]{2}{*}{ Daytime dysfunction } & Experimental & $0.84 \pm 0.8$ & $1(0-1)$ & 0.77 & $0.34 \pm 0.54$ & $0(0-0)$ & $\begin{array}{l}< \\
0.0001\end{array}$ & $\begin{array}{l}0.12 \pm \\
0.33\end{array}$ & $0(0-0)$ & $\begin{array}{l}< \\
0.0001\end{array}$ & $<0.001$ \\
\hline & Control & $\begin{array}{l}0.82 \pm \\
0.51\end{array}$ & $1(1-1)$ & & $1.20 \pm 0.79$ & $1(1-2)$ & & $\begin{array}{l}1.14 \pm \\
0.73\end{array}$ & $1(1-2)$ & & 0.02 \\
\hline \multirow[t]{2}{*}{ Global PSQI score } & Experimental & $\begin{array}{l}6.46 \pm \\
2.43\end{array}$ & $6.5(5-7)$ & 0.83 & $5.37 \pm 1.97$ & $5.5(4-7)$ & $\begin{array}{l}< \\
0.0001\end{array}$ & $\begin{array}{l}4.87 \pm \\
2.21\end{array}$ & $5(4-6)$ & $\begin{array}{l}< \\
0.0001\end{array}$ & $<0.001$ \\
\hline & Control & $\begin{array}{l}6.31 \pm \\
2.62\end{array}$ & $6(5-8)$ & & $7.62 \pm 2.51$ & $8(6-9)$ & & $\begin{array}{l}2.70 \pm \\
7.57\end{array}$ & $8(6-9)$ & & 0.03 \\
\hline
\end{tabular}

* Mann-Whitney

** Friedman test

${ }^{a}$ Mean \pm standard deviation, Expected range for each variable: $(0-3 ; 0=$ best result; $3=$ worst result $)$

${ }^{b}$ Median (Cl: Confidence Interval): correspond to their respective $95 \% \mathrm{Cl}$

Table 3 Effect of the Aerobic exercise intervention on fatigue as measured by the Multidimensional Fatigue Inventory questionnaire

\begin{tabular}{|c|c|c|c|c|c|c|c|c|}
\hline \multirow[t]{2}{*}{ Variable } & \multirow[t]{2}{*}{ Groups } & \multicolumn{2}{|l|}{ Baseline } & \multicolumn{2}{|c|}{4 weeks of Intervention } & \multicolumn{2}{|c|}{8 weeks of Intervention } & \multirow{2}{*}{$\begin{array}{l}\text { Friedman } \\
p \text {-value }\end{array}$} \\
\hline & & Mean \pm SD & $p$-value* & mean $\pm S D$ & $p$-value ${ }^{*}$ & mean $\pm S D$ & $p$-value ${ }^{*}$ & \\
\hline \multirow[t]{2}{*}{ General fatigue } & Experimental & $12.68 \pm 0.93$ & 0.49 & $10.12 \pm 1.60$ & $<0.001$ & $8.59 \pm 1.62$ & $<0.001$ & $<0.001$ \\
\hline & Control & $12.54 \pm 0.61$ & & $12.14 \pm 1.19$ & & $12.17 \pm 0.74$ & & 0.1 \\
\hline \multirow[t]{2}{*}{ Physical fatigue } & Experimental & $12.46 \pm 0.91$ & 0.66 & $9.84 \pm 1.54$ & $<0.001$ & $8.25 \pm 1.68$ & $<0.001$ & $<0.001$ \\
\hline & Control & $12.37 \pm 0.73$ & & $15.97 \pm 1.11$ & & $12.08 \pm 0.70$ & & 0.13 \\
\hline \multirow[t]{2}{*}{ Mental fatigue } & Experimental & $12.37 \pm 0.94$ & 0.37 & $9.68 \pm 1.59$ & $<0.001$ & $8.09 \pm 1.69$ & $<0.001$ & $<0.001$ \\
\hline & Control & $12.17 \pm 0.74$ & & $11.82 \pm 1.20$ & & $11.74 \pm 0.74$ & & 0.09 \\
\hline \multirow[t]{2}{*}{ Reduced activity } & Experimental & $12.25 \pm 0.95$ & 0.17 & $9.18 \pm 2.32$ & $<0.001$ & $7.90 \pm 1.71$ & $<0.001$ & $<0.001$ \\
\hline & Control & $11.94 \pm 0.63$ & & $11.60 \pm 1.21$ & & $11.54 \pm 0.70$ & & 0.04 \\
\hline \multirow[t]{2}{*}{ Reduced motivation } & Experimental & $11.96 \pm 0.86$ & 0.49 & $9.28 \pm 1.54$ & $<0.001$ & $7.46 \pm 1.79$ & $<0.001$ & $<0.001$ \\
\hline & Control & $11.80 \pm 0.58$ & & $11.37 \pm 1.16$ & & $11.54 \pm 0.70$ & & 0.06 \\
\hline \multirow[t]{2}{*}{ Global MFI score } & Experimental & $61.87 \pm 4.38$ & 0.27 & $48.40 \pm 7.77$ & $<0.001$ & $40.62 \pm 8.27$ & $<0.001$ & $<0.001$ \\
\hline & Control & $60.85 \pm 2.86$ & & $48.40 \pm 7.77$ & & $58.91 \pm 3.35$ & & 0.007 \\
\hline
\end{tabular}


improvement in sleep duration was not significant after 4 weeks of intervention. It seems that increasing the intensity of exercise from mild to moderate enhanced all aspects of sleep quality. Also, after four and 8 weeks of intervention, an aerobic exercise decreased the total fatigue score and its components. Since both control and experimental groups underwent midterm exams, the exercise intervention was also able to positively affect the sleep quality during the exams period. The preventive role of exercise in this regard should also be emphasized due to its clinical applications.

The majority of the studies show positive impact of aerobic exercise on sleep quality in students, with one single exception. Studies show that exercise significantly improved sleep quality among students [23, 24]. However in an Iranian quasi-experimental study, at least three sessions per week for 3 months of intervention in 48 students (24 female and 24 male) had no significant influence on sleep quality in either gender [20]. The difference in findings can be attributed to confounding factors (i.e., marital and employment status, household type, intake of herbal medicine, and exercise type which were not disclosed in the study.

The varying intensity levels of physical activity may affect sleep quality differently. Moderate-intensity exercise is generally defined at $65-70 \%$ of maximal heart rate [36]. Our results revealed that increasing the intensity of exercise from mild to moderate after 4 weeks could improve sleep quality. According to consultation with sports science expert, the intervention should be designed from mild to moderate activity for participants who did not exercise regularly. Our results revealed that increasing the intensity of exercise from mild to moderate after 4 weeks could improve sleep quality. Consistent with our results, several studies report the benefits of moderate physical activity on sleep [18, 23, 37-40]. A systematic review also showed that moderate exercise has promising outcomes on sleep quality [41]. Thus, examining exercise intensity is imperative to understanding the linkage between physical activity and sleep.

Time of day is also a critical components of exercise [39]. In the present study, early evening exercise increased sleep quality. Morin et al. similarly found that physical activity early in the evening improves the quality of sleep [42]. Results from a systematic review and meta-analysis showed that moderate evening exercise may have positive impact on sleep [43]. Further studies are required to examine the effects of exercise at different times of day on sleep quality.

Concerning the frequency of physical activity, consistent with our results, some studies found that regular physical activity can lead to a more efficient sleep period [44, 45]. A survey reported a positive association between increased frequency of exercise and sleep in young adults [43]. Wu et al. did not observe an association between physical activity and better sleep quality [46]. In a study surveying athletes, 1 day without physical activity had harmed subsequent sleep [47], concluding the benefits of frequent engagement in physical activity on sleep.

According to our findings, four and 8 weeks of aerobic exercises also improved fatigue level and its components in university students. De. Veris's study revealed significant beneficial effects of aerobic exercises on fatigue level of university students [48]. In one study of multiple sclerosis patients, aerobic exercises significantly reduced fatigue level compared the control group [28]. Physical activity in individuals with pulmonary arterial hypertension could also reduce fatigue severity [14].

Generally, the results of various surveys show that physical activity may decrease fatigue level and promote sleep quality through various mechanisms. Perhaps the most possible mechanism could be attributed to anxiety reduction through exercise [49]. Sleep might also serve as a down-regulation function. During the sleep period, decrease in body temperature occurs as a normal biological process. Given that physical activity increases body temperature, the body seeks to regain its homeostasis and thereby uses the same processes during the sleep period to decrease body temperature by dilation of blood vessels and increased blood flow to the peripheral regions of the body [50]. This process therefore acts as a catalyst of sleep initiation. Moreover, studies showed the anti-depressant effects of exercise which mediated by nightly increases of non-rapid eye movement (NREM) and decreases in REM sleep as well as alteration of Slow-wave sleep (SWS) through temperature elevation $[49,51]$. Exercise is often advocated for physiological health benefits and could improve mental health by affecting fatigue level [52]. Additionally, physical activity could impact sleep through the cardiac system by accelerating the re- entrainment to a shifted light-dark cycle [49].

\section{Conclusions}

Poor quality sleep and daily fatigue are prevailing among dormitory students, especially female students. Therefore, non-pharmacological approaches are recommended due to their low-risk and accessibility. Aerobic exercise activities is one of the suggested strategies. Given the findings of the present study, performing a regular aerobic exercise with increasing its intensity is recommended as a practical approach to improve fatigue and sleep quality in non-athletic students.

\section{Limitations}

The inconsistencies in daily sleep hours and daily routines among study participants need to be considered during the interpretation of the results. 


\section{Abbreviations}

AASM: American Academy of Sleep Medicine; PSQI): Pittsburgh Sleep Quality Index; MFI-20: Multidimensional Fatigue Inventory; IUMS: Iran University of Medical Sciences; IRCT: Iranian Registry of Clinical Trials; SWS: Slow-wave sleep

\section{Acknowledgements}

The authors are grateful to all participants in this study for their trustworthy cooperation and giving their time and the aerobic trainer who monitored the process of the students' physical activity, also thanks Dr. Khosro Ebrahim, Professor, Shahid Beheshti University of Medical Sciences, for his advice on choosing the type of aerobic exercise intervention. This study was submitted as partial fulfillment of the MSc thesis of midwifery which was supported by Iran University of Medical Sciences (IUMS).

\section{Authors' contributions}

ME and MK participated in the design of the study, acquisition and analysis of the data and writing of the manuscript. $Z A B$ contributed in writing the manuscript, and consultant in all part of the study. AM verified the analytical methods and contributed to the interpretation of the results. All authors read and approved the final version of the submitted manuscript.

\section{Funding}

The study was supported by Iran University of Medical Sciences (IUMS). The funding source was used for the data collection, and analysis.

\section{Availability of data and materials}

The datasets used and/or analyzed during the current study are available from the corresponding author on reasonable request.

\section{Ethics approval and consent to participate}

The study was approved by the ethical committee of Iran University of Medical Sciences with ethical code number 110427. The study was registered on 6/2/2015 in the Iranian Registry of Clinical Trials (IRCT) with number IRCT201412282324N15. The written informed consent was obtained from all participants. In the form, the participants had given their consent for publishing the study data. They were informed that their names and characteristics will not be published.

\section{Consent for publication}

Not applicable.

\section{Competing interests}

The authors declare that they have no competing interests.

\section{Author details}

${ }^{1}$ Department of Midwifery and Reproductive Health, Faculty of Nursing and Midwifery, Iran University of Medical Sciences, Tehran, Iran. ${ }^{2}$ School of Nursing, University of Connecticut, Storrs, CT, USA. ${ }^{3}$ Population Health Research Group, Health Metrics Research Center, Iranian Institute for Health Sciences Research, ACECR, Tehran, Iran.

Received: 31 December 2019 Accepted: 14 July 2020

Published online: 05 August 2020

\section{References}

1. Panel CC, et al. Joint consensus statement of the American Academy of sleep medicine and Sleep Research Society on the recommended amount of sleep for a healthy adult: methodology and discussion. Sleep. 2015;38(8): $1161-83$.

2. Medic G, Wille M, Hemels ME. Short-and long-term health consequences of sleep disruption. Nat Sci Sleep. 2017;9:151.

3. Jaiswal SJ, Owens RL, Malhotra A. Raising awareness about sleep disorders. Lung India. 2017;34(3):262.

4. Gaultney JF. The prevalence of sleep disorders in college students: impact on academic performance. J Am Coll Heal. 2010;59(2):91-7.

5. Lund $H G$, et al. Sleep patterns and predictors of disturbed sleep in a large population of college students. J Adolesc Health. 2010;46(2):124-32.

6. Ghoreishi A, Aghajani AH. Sleep quality in Zanjan university medical students. Tehran Univ Med J. 2008;66(1):61-7.
7. Qin P, Brown CA. Sleep practices of university students living in residence. Int J Higher Educ. 2017;6(5):14-25.

8. Haase A, et al. Leisure-time physical activity in university students from 23 countries: associations with health beliefs, risk awareness, and national economic development. Prev Med. 2004;39(1):182-90.

9. Farmanbar $\mathrm{R}$, et al. Predicting exercise behaviour in Iranian college students: utility of an integrated model of health behaviour based on the transtheoretical model and self-determination theory. Health Educ J. 2013; 72(1):56-69.

10. Sateia MJ, et al. Clinical practice guideline for the pharmacologic treatment of chronic insomnia in adults: an American Academy of sleep medicine clinical practice guideline. J Clin Sleep Med. 2017;13(02):307-49.

11. Dolezal BA, Neufeld EV, Boland DM, Martin JL, Cooper CB. Interrelationship between sleep and exercise: A systematic review Adv Prev Med. 2017;2017: 1364387.

12. Roveda $E$, et al. Protective effect of aerobic physical activity on sleep behavior in breast cancer survivors. Integr Cancer Ther. 2017;16(1):21-31.

13. Aoike DT, Baria F, Kamimura MA, Ammirati A, Cuppari L. Home-based versus center-based aerobic exercise on cardiopulmonary performance, physical function, quality of life and quality of sleep of overweight patients with chronic kidney disease. Clin Exp Nephrol. 2018:22(1):87-98.

14. Weinstein AA, et al. Effect of aerobic exercise training on fatigue and physical activity in patients with pulmonary arterial hypertension. Respir Med. 2013;107(5):778-84

15. Løppenthin K, et al. Effect of intermittent aerobic exercise on sleep quality and sleep disturbances in patients with rheumatoid arthritis - design of a randomized controlled trial. BMC Musculoskelet Disord. 2014;15(1):49.

16. Khoshnam E, Shokri F, Nikseresht A. The effect of eight weeks of aerobic exercise on depression, anxiety and sleep disorders in middle-aged women. Eur J Exp Biol. 2014;4(1):557-9.

17. Akbari Kamrani AA, et al. The effect of low and moderate intensity aerobic exercises on sleep quality in men older adults. Pakistan J Med Sci. 2014; 30(2):417-21.

18. Kashefi Z, Mirzaei B, Shabani R. The effects of eight weeks selected aerobic exercises on sleep quality of middle-aged non-athlete females. Iran Red Crescent Med J. 2014:16(7):e16408.

19. Mansikkamäki $K$, et al. Sleep quality and aerobic training among menopausal women - a randomized controlled trial. Maturitas. 2012;72(4): 339-45.

20. Soltani Shal R, Sharbaf HA, chamanabad AG. Effect of exercise on general health, quality of sleep and quality of life in Ferdowsi University of Mashhad students. J Qazvin Univ Med Sci. 2013;17(4):39-46.

21. Gerber $\mathrm{M}$, et al. Fitness and exercise as correlates of sleep complaints: is it all in our minds? Med Sci Sports Exerc. 2010;42(5):893-901.

22. Wunsch K, Kasten N, Fuchs R. The effect of physical activity on sleep quality, well-being, and affect in academic stress periods. Nat Sci Sleep. 2017;9:117.

23. Kianian T, et al. Comparing the effects of aerobic and anaerobic exercise on sleep quality among male nonathlete students. Nurs Midwifery Stud. 2017; 6(4):168-73.

24. Delisle $\Pi$, et al. Relationship between frequency and intensity of physical activity and health behaviors of adolescents. J Sch Health. 2010;80(3):134-40.

25. Regestein Q, et al. Sleep debt and depression in female college students. Psychiatry Res. 2010;176(1):34-9.

26. Sundelin T, et al. Cues of fatigue: effects of sleep deprivation on facial appearance. Sleep. 2013;36(9):1355-60.

27. Eyigor $\mathrm{S}$, et al. Effects of pilates exercises on functional capacity, flexibility, fatigue, depression and quality of life in female breast cancer patients: a randomized controlled study. Eur J Phys Rehabil Med. 2010;46(4):481-7.

28. Pazokian M, Shaban M, Zakerimoghdam M, Mehran A, Sangelagi B. A comparison between the effect of stretching with aerobic and aerobic excercises on fatigue level of multiple sclerosis patients. Qum Univ Med Sci. 2013;7(1):50-6.

29. Buysse DJ, et al. The Pittsburgh sleep quality index: a new instrument for psychiatric practice and research. Psychiatry Res. 1989;28(2):193-213.

30. Farrahi Moghaddam J, et al. Reliability and validity of the Persian version of the Pittsburgh Sleep Quality Index (PSQI-P). Sleep Breath. 2012;16(1):79-82.

31. Manzar MD, et al. Validity of the Pittsburgh sleep quality index in Indian University students. Oman Med J. 2015;30(3):193-202.

32. Spira AP, et al. Reliability and validity of the Pittsburgh Sleep Quality Index and the Epworth Sleepiness Scale in older men. J Gerontol A, Biol Sci Med Sci. 2012;67(4):433-9. 
33. Moghaddam JF, et al. Reliability and validity of the Persian version of the Pittsburgh sleep quality index (PSQI-P). Sleep Breathing. 2012;16(1):79-82.

34. Schneider RA. Reliability and validity of the Multidimensional Fatigue Inventory (MFI-20) and the Rhoten fatigue scale among rural cancer outpatients. Cancer Nurs. 1998;21(5):370-3.

35. Pazokian M, et al. Comparison between the effect of stretching with aerobic and aerobic exercises on fatigue level in multiple sclerosis patients. Qom Univ Med Sci J. 2013;7(1):50-6.

36. Dworak $\mathrm{M}$, et al. Increased slow wave sleep and reduced stage 2 sleep in children depending on exercise intensity. Sleep Med. 2008;9(3):266-72.

37. Flausino NH, et al. Physical exercise performed before bedtime improves the sleep pattern of healthy young good sleepers. Psychophysiology. 2012; 49(2):186-92.

38. Kobayashi T, et al. Effects of the late evening exercise on sleep onset process. Sleep Res Online. 1999:2(suppl 1):233.

39. Kalak N, et al. Daily morning running for 3 weeks improved sleep and psychological functioning in healthy adolescents compared with controls. J Adolesc Health. 2012;51(6):615-22.

40. Hurdiel $R$, et al. Effects of a 12-week physical activities programme on sleep in female university students. Res Sports Med. 2017;25(2):191-6.

41. Wang F, Boros S. The effect of physical activityon sleep quality: a systematic review. Eur J Physiother.. https://doi.org/10.1080/21679169.2019.1623314.

42. Morin CM, et al. Nonpharmacologic treatment of chronic insomnia. Sleep. 1999;22(8):1134-56.

43. Tatum J. The relationship between physical activity and sleep (unpublished doctoral thesis). Denton: University of North Texas; 2011.

44. Leopoldino AAO, et al. Effect of Pilates on sleep quality and quality of life of sedentary population. J Bodyw Mov Ther. 2013;17(1):5-10.

45. Brand S, et al. Exercising, sleep-EEG patterns, and psychological functioning are related among adolescents. World J Biol Psychiatry. 2010;11(2):129-40.

46. Wu X, et al. Low physical activity and high screen time can increase the risks of mental health problems and poor sleep quality among Chinese college students. PLoS One. 2015;10(3):e0119607.

47. Hague JF, et al. A sedentary day: effects on subsequent sleep and body temperatures in trained athletes. Physiol Behav. 2003;78(2):261-7.

48. de Vries JD, et al. Exercise as an intervention to reduce study-related fatigue among university students: a two-arm parallel randomized controlled trial. PLoS One. 2016;11(3):e0152137.

49. Youngstedt SD. Effects of exercise on sleep. Clin Sports Med. 2005;24(2): 355-65.

50. Taylor SR. The influence of exercise on sleep quality. Int SportMed J. 2001; 2(3):1-10.

51. Uchida S, et al. Exercise effects on sleep physiology. Front Neurol. 2012;3:48.

52. Puetz TW, O'Connor PJ, Dishman RK. Effects of chronic exercise on feelings of energy and fatigue: a quantitative synthesis. Psychol Bull. 2006;132(6):866.

\section{Publisher's Note}

Springer Nature remains neutral with regard to jurisdictional claims in published maps and institutional affiliations.

Ready to submit your research? Choose BMC and benefit from:

- fast, convenient online submission

- thorough peer review by experienced researchers in your field

- rapid publication on acceptance

- support for research data, including large and complex data types

- gold Open Access which fosters wider collaboration and increased citations

- maximum visibility for your research: over $100 \mathrm{M}$ website views per year

At $\mathrm{BMC}$, research is always in progress.

Learn more biomedcentral.com/submissions 